\title{
Front Matter: Volume 6833
}

, "Front Matter: Volume 6833," Proc. SPIE 6833, Electronic Imaging and Multimedia Technology V, 683301 (26 February 2008); doi:

10.1117/12.784618

SPIE. Event: Photonics Asia 2007, 2007, Beijing, China 


\title{
PROCEEDINGS OF SPIE
}

\section{Electronic Imaging and Multimedia Technology $V$}

\author{
Liwei Zhou \\ Chung-Sheng Li \\ Minerva M. Yeung \\ Editors
}

\section{2-15 November 2007 \\ Beijing, China}

Sponsored by

SPIE • COS-Chinese Optical Society

Cooperating Organizations

OSJ-Optical Society of Japan • OSK-Optical Society of Korea • Australian Optical Society • Optical Society of Singapore • Beijing Institute of Technology (China) • Beijing University of Posts and Telecommunications (China) • Peking University (China) • Tsinghua University (China) • Zhejiang University (China) • Changchun University of Science and Technology (China) • University of Shanghai for Science and Technology (China) • Shanghai Jiao Tong University (China) • Tianjin University (China) Nankai University (China) • Shanghai Institute of Optics and Fine Mechanics (China) • Changchun Institute of Optics and Fine Mechanics (China) • Institute of Semiconductors (China) • Institute of Optics and Electronics (China) - Shanghai Institute of Technical Physics (China) • China Instrument and Control Society • China Solid State Lighting Research and Industry Alliance • Optoelectronics Technology Committee, COS (China)

\section{Supporting Organizations}

CAST-China Association for Science and Technology (China) • NNSF-National Nature Science Foundation (China) • The Ministry of Science and Technology (China)

Published by

SPIE

Part One of Two Parts

Volume 6833 
The papers included in this volume were part of the technical conference cited on the cover and title page. Papers were selected and subject to review by the editors and conference program committee. Some conference presentations may not be available for publication. The papers published in these proceedings reflect the work and thoughts of the authors and are published herein as submitted. The publisher is not responsible for the validity of the information or for any outcomes resulting from reliance thereon.

Please use the following format to cite material from this book:

Author(s), "Title of Paper," in Electronic Imaging and Multimedia Technology V, edited by Liwei Zhou, Chung-Sheng Li, Minerva M. Yeung, Proceedings of SPIE Vol. 6833 (SPIE, Bellingham, WA, 2007) Article CID Number.

ISSN 0277-786X

ISBN 9780819470089

Published by

SPIE

P.O. Box 10, Bellingham, Washington $98227-0010$ USA

Telephone +1 3606763290 (Pacific Time) · Fax +1 3606471445

SPIE.org

Copyright (c) 2008, Society of Photo-Optical Instrumentation Engineers

Copying of material in this book for internal or personal use, or for the internal or personal use of specific clients, beyond the fair use provisions granted by the U.S. Copyright Law is authorized by SPIE subject to payment of copying fees. The Transactional Reporting Service base fee for this volume is $\$ 18.00$ per article (or portion thereof), which should be paid directly to the Copyright Clearance Center (CCC), 222 Rosewood Drive, Danvers, MA 01923. Payment may also be made electronically through CCC Online at copyright.com. Other copying for republication, resale, advertising or promotion, or any form of systematic or multiple reproduction of any material in this book is prohibited except with permission in writing from the publisher. The CCC fee code is 0277-786X/08/\$18.00.

Printed in the United States of America.

Publication of record for individual papers is online in the SPIE Digital Library.

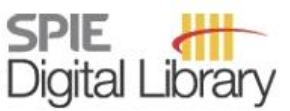

SPIEDigitalLibrary.org

Paper Numbering: Proceedings of SPIE follow an e-First publication model, with papers published first online and then in print and on CD-ROM. Papers are published as they are submitted and meet publication criteria. A unique, consistent, permanent citation identifier (CID) number is assigned to each article at the time of the first publication. Utilization of CIDs allows articles to be fully citable as soon they are published online, and connects the same identifier to all online, print, and electronic versions of the publication. SPIE uses a six-digit CID article numbering system in which:

- The first four digits correspond to the SPIE volume number.

- The last two digits indicate publication order within the volume using a Base 36 numbering system employing both numerals and letters. These two-number sets start with 00, 01, 02, 03, 04, 05, $06,07,08,09,0 \mathrm{~A}, 0 \mathrm{~B} \ldots \mathrm{OZ}$, followed by $10-1 \mathrm{Z}, 20-2 \mathrm{Z}$, etc.

The CID number appears on each page of the manuscript. The complete citation is used on the first page, and an abbreviated version on subsequent pages. Numbers in the index correspond to the last two digits of the six-digit CID number. 


\title{
Contents
}

\author{
xiii Symposium Committees \\ xv Conference Committee \\ xvii Introduction
}

\section{Part One}

\section{SESSION 1 ELECTRONIC IMAGING SYSTEMS}

683302 Photo-collection representation based on viewpoint clustering (Invited Paper) [6833-87]

A. Sibiryakov, Mitsubishi Electric ITE B.V. (United Kingdom)

683303 High speed real-time wavefront processing system for a solid-state laser system [6833-48] Y. Liu, P. Yang, S. Chen, L. Ma, Institute of Optics and Electronics (China) and Graduate School of Chinese Academy of Sciences (China); B. Xu, Institute of Optics and Electronics (China)

683305 Research on the two dimension performance model for low light level imaging systems [6833-42]

K. Ai, Xi'an Institute of Applied Optics (China); L. Zhou, Beijing Institute of Technology (China)

683306 Study on simulation of low light level images and photon images [6833-71]

L. Zhao, X. Yu, Y. Chen, Beijing Institute of Technology (China)

683307 Automatic optical inspection for chip components based on local principal wave probability [6833-129]

J. Wu, Huazhong Univ. of Science and Technology (China); F. Sun, Huazhong Institute of Electro-Optics (China); Y. Wang, Huazhong Univ. of Science and Technology (China)

683308 Network video transmission system based on SOPC [6833-64]

Z. Zhang, H. Deng, Z. Xia, Yangtze Univ. (China)

683309 A 3D model retrieve method integrating shape distribution and self-organizing feature map [6833-61]

M. Huang, H. Jing, Y. Zhong, B. Kuang, Guilin Univ. of Electronic Technology (China)

$68330 \mathrm{~A}$ The application of coded excitation technology in medical ultrasonic Doppler imaging [6833-47]

W. Li, X. Chen, J. Bao, D. Yu, Tianjin Univ. (China) 
6833 OB Integrated optical 3D digital imaging based on DSP scheme (Invited Paper) [6833-55] X. Wang, X. Peng, Shenzhen Univ. (China) and Tianjin Univ. (China); B. Z. Gao, Clemson Univ. (USA)

6833 OC Embedded video monitoring system based on the OMAP [6833-58]

Z.-H. Xia, T.-T. Pan, Z.-B. Zhang, Yangtze Univ. (China)

6833 OD Elimination of intra-page crosstalk noise in holographic data storage by using pixelmatched spread function [6833-120]

H. Wang, S. Tao, Y. Wan, Z. Jiang, D. Wang, Beijing Univ. of Technology (China)

$6833 \mathrm{OE} \quad$ An image quality assessment algorithm used for JPEG compressed image [6833-73]

R. Li, Q. Huang, Y. Lu, Beijing Institute of Technology (China)

6833 OF The system integration of image processing [6833-141]

Q. Chen, Institute of Optics and Electronics (China) and Graduate School of the Chinese Academy of Sciences (China); Q. Wu, X. Gao, G. Ren, Institute of Optics and Electronics (China)

6833 OG An improved SUSAN algorithm for electronic image stabilization of the UAV video image [6833-105]

H. Zhao, Peking Univ. (China); Y. Cheng, G. Li, China Univ. of Mining and Technology (China)

$6833 \mathrm{OH} \quad$ A new method for stabilization of video images with large moving object [6833-103]

P. Gao, L. Yan, H. Zhao, Peking Univ. (China)

\section{SESSION 3 IMAGE PROCESSING II}

6833 0J Despeckling algorithm on ultrasonic image using adaptive block-based singular value decomposition (Invited Paper) [6833-20]

N. Sae-Bae, S. Udomhunsakul, King Mongkut's Institute of Technology Ladkrabang (Thailand)

6833 OK A nonlinear prediction filter algorithm based on the adaptive tracking theory [6833-142] M. Xiong, Institute of Optics and Electronics (China) and Graduate Univ. of Chinese Academy of Sciences (China); Q. Wu, X. Gao, Institute of Optics and Electronics (China)

$6833 \mathrm{OL}$ Analysis of the enrichment jet plane engine's UV image histogram [6833-19] S. Chang, X. Shen, J. Yang, J. Yang, National Univ. of Defense Technology (China)

6833 OM A novel eyelid detection method for iris segmentation [6833-52] Y. Wang, T. Liu, J. Jiang, Tianjin Univ. (China)

$6833 \mathrm{ON}$ Size measurement of standing and sitting position based on human animation [6833-123] X. Li, Q. Tian, B. Ge, Y. Wei, Q. Lü, Tianjin Univ. (China)

683300 Subaperture algorithm for airborne spotlight SAR imaging with nonideal motions [6833-128] Y. Li, D. Zhu, Nanjing Univ. of Aeronautics and Astronautics (China) 
6833 OP A new sub-pixel imaging algorithm based on multi-resolution filtering and its real-time realizing technology [6833-62]

J. Zhang, Security Printing Institute of People's Bank of China (China); G. Ni, Beijing Institute

of Technology (China); X. Liu, Xi'an Institute of Optics and Precision Mechanics (China)

$68330 Q \quad$ Two fast algorithms of image inpainting [6833-99]

Y. He, Z. Hou, C. Wang, Tianjin Univ. (China)

6833 OS A scale rotation adaptive new mean shift tracking method [6833-97]

H. Zhang, L. Li, Y. Li, Q. YU, National Univ. of Defense Technology (China)

SESSION 4 TARGET DETECTION AND IMAGE REGISTRATION

6833 OT A vision-based detection algorithm for unmarked road [6833-75]

Q. Gao, Nanjing Univ. of Aeronautics and Astronautics (China) and Civil Aviation Univ. of China (China); M. Sun, X. Si, Northeast Dianli Univ. (China); G. Yang, Nanjing Univ. of Aeronautics and Astronautics (China)

6833 OV Road and linear structure automatic extraction [6833-102]

Q. Hao, X. Chen, G. Ni, H. Zhang, Beijing Institute of Technology (China)

$6833 \mathrm{OW} \quad$ Fast Hough transform for automatic bridge extraction [6833-83]

Q. Hao, X. Chen, G. Ni, H. Zhang, Beijing Institute of Technology (China)

6833 0X A coarse registration method of range image based on SIFT [6833-68]

X. Liu, Shenzhen Univ. (China) and Tianjin Univ. (China); X. Peng, Y. Yin, J. Tian, A. Li, X. Zhao, Shenzhen Univ. (China)

6833 OY Research on registration algorithm for check seal verification [6833-104]

S. Wang, Tianjin Univ. (China) and Research Institute of Physical and Chemical Engineering of Nuclear Industry (China); T. Liu, Tianjin Univ. (China)

$68330 Z$ Image matching based on epipolar and local homography constraints [6833-115]

L. Li, H. Zhang, D. Fu, Y. Li, Q. YU, National Univ. of Defense Technology (China)

\section{SESSION 5 IMAGE RECOGNITION AND FUSION}

683310 Fast intellective recognition of autocar tire character based on canny operator [6833-03] Z. Huang, J. Yang, Z. Liu, T. Zhao, Tianjin Univ. (China)

683311 Analysis on niche genetic algorithm based nonparametric curve recognition [6833-04] W. Wei, M. Yu, X. Yang, Hebei Univ. of Technology (China)

683312 Online recognition of group actions in intelligent meeting scenario [6833-136]

$X$. Zhang, Yangtze Univ. (China) and Tsinghua Univ. (China); X. Luo, Univ. Of Science and Technology Beijing (China); L. Tao, G. Xu, Tsinghua Univ. (China) 
683314 Rock images classification using principle component analysis and spatial frequency measurement [6833-77]

T. Kachanubal, S. Udomhunsakul, King Mongkut's Institute of Technology Ladkrabang (Thailand)

683315 An improved fusion algorithm of video sequences based on IR and visible [6833-81] F. Zhou, W. Cheng, X. Lu, Xi'an Institute of Applied Optics (China)

683316 Implementation of real-time Laplacian pyramid image fusion processing based on FPGA [6833-86]

Y. Song, K. Gao, G. Ni, R. Lu, Beijing Institute of Technology (China)

683317 An image fusion of quincunx sampling lifting scheme and small real-time DSP-based system [6833-96]

Q. Wang, Beijing Institute of Technology (China) and China Ordnance Equipment Group 208 Institute (China); G. Ni, Beijing Institute of Technology (China); B. Chen, China Ordnance Equipment Group 208 Institute (China)

683318 An image segmentation approach based on chaotic ant colony algorithms [6833-84] Z. Pan, L. Chen, South China Normal Univ. (China)

683319 A hybrid image segmentation algorithm based on edge detection, thresholding, and region growing [6833-89]

Z. Xie, Fujian Normal Univ. (China); G. Chen, Fujian Normal Univ. (China) and Huazhong Univ. of Science and Technology (China); R. Chen, J. Lei, S. Feng, Z. Huang, W. Lin, Fujian Normal Univ. (China)

\section{SESSION 6 COLOR IMAGE PROCESSING AND CODING}

6833 1B New color image processing with color filter array for single chip camera [6833-27]

J. J. Wang, R. F. Li, Z. Wang, W. Y. Liu, Tianjin Univ. (China)

$68331 \mathrm{C}$ Color image quality metric for realistic image rendition [6833-101]

M. Xiao, S.-Y. Chen, G. Ni, Beijing Institute of Technology (China)

6833 ID Color transfer based on steerable pyramid and hot contrast for visible and infrared images [6833-110]

L. Wang, Y. Zhao, W. Jin, S. Shi, Beijing Institute of Technology (China)

6833 IE Low-complexity multiple ROI image coding method based on different degrees of interest [6833-40]

L. Zhang, Beijing Normal Univ. (China)

6833 1G Fractional Lévy stable motion for modeling speckle image [6833-92]

X. Li, L. Jin, South China Univ. of Technology (China); F. Peng, Huazhong Univ. of Science and Technology (China); A. Zhu, Guangdong Univ. of Technology (China)

$68331 \mathrm{H} \quad$ Frame transfer CCD driving circuit design for space camera [6833-90]

X. Chen, J. Zhou, W. Zhou, W. Shen, Suzhou Univ. (China) 
$68331 \mathrm{~K}$ Robust non-rigid registration of medical images with incomplete image information using local structure-adaptive block matching method [6833-01]

Z. Zhou, B. Qin, Shanghai Jiao Tong Univ. (China)

6833 1L DSP implementation of wavelet image enhancement [6833-05]

W. Bai, B. Zhang, Tianjin Univ. of Technology (China); Q. Bai, Tianjin Institute of Urban Construction (China)

$68331 \mathrm{M}$ Point spread function estimation based on wavelet transform for image restoration [6833-06]

X. Chen, Z. Fan, Harbin Institute of Technology (China)

6833 iN Proposals to set up the new performance model for thermal imaging systems [6833-09]

K. Ai, Xi'an Institute of Applied Optics (China); L. Zhou, Beijing Institute of Technology

(China); X. Li, C. Wang, Xi'an Institute of Applied Optics (China)

\section{Part Two}

683310 Air touch: new feeling touch-panel interface you don't need to touch using audio input [6833-10]

K. Sakamoto, H. Morimoto, Shimane Univ. (Japan)

$68331 \mathrm{P} \quad$ Liquid crystal layer enables to provide virtual display using mirror image of polarized display monitor for extension of screen region [6833-11]

K. Sakamoto, A. Tanaka, Shimane Univ. (Japan)

6833 IQ Arenani: pointing and information query system for object beyond your reach [6833-12] M. Adachi, K. Sakamoto, Shimane Univ. (Japan)

6833 IR Deco-video: video editing and viewing browser enables to playback movie contents reproduced by using scene scenario [6833-13]

T. Ishihara, K. Sakamoto, Shimane Univ. (Japan)

6833 is Light path indication system for route guidance in public facilities [6833-14]

H. Fukuda, K. Sakamoto, Shimane Univ. (Japan)

6833 IT Handheld route guidance system using projected direction indicator for outdoor usage [6833-15]

K. Sakamoto, K. Uchida, Shimane Univ. (Japan)

$68331 \mathrm{U}$ Multiframe blind deconvolution of atmospheric turbulence-degraded images based on filter [6833-21]

J. Huang, Institute of Optics and Electronics (China) and Graduate School of Chinese Academy of Sciences (China); M. Shen, Q. Li, Institute of Optics and Electronics (China)

6833 IW The research of smearing elimination of remote sensing images [6833-23]

Y. Chen, W. Zhou, W. Shen, Soochow Univ. (China) 
$68331 \mathrm{X}$ Research of X-ray nondestructive detector for high-speed running conveyor belt with steel wire ropes [6833-25]

J. Wang, C. Miao, W. Wang, X. Lu, Tianjin Polytechnic Univ. (China)

6833 IY Online maintaining appearance model using particle filter [6833-28]

S. Chen, T. Lan, Beijing Institute of Technology (China); J. Wang, Institute of Computing Technology (China); G. Ni, Beijing Institute of Technology (China)

$68331 \mathrm{I}$ Image segmentation based on double-level parallelized firing PCNN in complex environments [6833-30]

B. Jiang, Z. Peng, J. Xiao, H. Wang, Univ. of Electronic Science and Technology of China (China)

683320 Robust adaptive non-rigid image registration based on joint salient point sets in the presence of tumor-like gross outliers [6833-32]

B. Qin, Z. Gu, Shanghai Jiao Tong Univ. (China)

$683321 \quad$ Video surveillance system based on MPEG-4 [6833-33]

J. Ge, G. Zhang, Z. Yang, Huazhong Normal Univ. (China)

683322 IFS-based image geometry transform [6833-34]

Z. Zhang, X. Xiong, Z. Xia, Yangtze Univ. (China)

683323 Analysis of images in dielectric electric discharge [6833-35]

Y. He, L. Dong, H. Yue, W. Fan, H. Zhao, L. Yang, Hebei Univ. (China)

683324 Research on adaptive Kalman filtering based on interacting multiple model [6833-36]

Y. Zhang, Institute of Optics and Electronics (China) and Graduate School of the Chinese Academy of Sciences (China); Q. Wu, Institute of Optics and Electronics (China)

683326 Medical image compression based on subband information statistic model [6833-39]

L. Zhang, Beijing Normal Univ. (China)

683327 An ROI-codec-supported rate control algorithm in video compression [6833-41]

Z. Li, S. Jin, China Jiliang Univ. (China)

683328 A symbol-map wavelet zero-tree image coding algorithm [6833-43]

X. Wang, Tianjin Univ. (China) and Shenzhen Univ. (China); W. Liu, Tianjin Univ. (China);

X. Peng, X. Liu, Tianjin Univ. (China) and Shenzhen Univ. (China)

683329 Development of low light level and wide dynamic range visible nephogram imaging technology [6833-45]

W. Xu, H. Fan, T. Liu, Donghua Univ. (China); J. Wei, D. Weng, Shanghai Institute of Technical Physics (China)

6833 2A Fast content-based image retrieval using dynamic cluster tree [6833-46]

J. Chen, J. Sun, R. Wu, Y. Zhang, Tianjin Univ. (China) 
$68332 \mathrm{~B} \quad$ A robust approach for detecting infrared small dim targets [6833-49]

Y. Yong, Univ. of Electronic Science and Technology of China (China); X. Yang, B. Wang, Chongaing Military Deputy Bureau (China); Z. Peng, Univ. of Electronic Science and Technology of China (China)

$68332 \mathrm{C}$ A method of improving the accuracy of sub-pixel localization in digital image measurement [6833-50]

J. Zhang, Institute of Optics and Electronics (China) and Graduate School of Chinese

Academy of Sciences (China); Q. Zhang, Institute of Optics and Electronics (China)

$68332 \mathrm{D}$ Application of a partial differential equation in image processing [6833-53]

H. Wang, Z. Yin, J. Wan, J. Pang, North China Electric Power Univ. (China)

$68332 \mathrm{E}$ Research on on-line grading system for pearl defect based on machine vision [6833-54]

J. Zhou, L. Ma, Hangzhou Dianzi Univ. (China)

$68332 \mathrm{~F}$ Video semantics discovery from video captions and comments [6833-56]

R. Wu, J. Sun, J. Chen, H. Wu, Tianjin Univ. (China)

$68332 \mathrm{G}$ Real-time distortion correction for visual inspection systems based on FPGA [6833-57]

D. Liang, Z. Zhang, X. Chen, D. YU, Tianjin Univ. (China)

$68332 \mathrm{H} \quad$ Fabrication and characterization of large area mercuric iodide polycrystalline films [6833-60]

J. Gui, Huazhong Univ. of Science and Technology (China) and Shenzhen Univ. (China);

J. Guo, Q. Yang, X. Liu, H. Niu, Shenzhen Univ. (China)

$683321 \quad$ Low-contrast small target image enhancement based on rough set theory [6833-63]

Y. Yong, Univ. of Electronic Science and Technology of China (China); B. Wang, W. Zhang, Chongqing Military Deputy Bureau (China); Z. Peng, Univ. of Electronic Science and Technology of China (China)

$68332 \mathrm{~J}$ Research on 3D visualization of fault diagnosis system for photoelectric tracking devices [6833-76]

M. Hou, Institute of Optics and Electronics (China) and Graduate School of the Chinese Academy of Sciences (China); Q. Wu, Institute of Optics and Electronics (China); Y. Liu, Q. Chen, Institute of Optics and Electronics (China) and Graduate School of the Chinese Academy of Sciences (China)

$68332 \mathrm{~K}$ Design and implementation of timing generator of frame transfer area-array CCD camera [6833-78]

J. Zhou, X. Chen, W. Zhou, W. Shen, Soochow Univ. (China) and Jiangsu Key Lab. of Modern Optical Technology (China)

$68332 \mathrm{~L}$ Research on the measuring technology of minute part's geometrical parameter based on image processing [6833-79]

X. Jia, Z. Xiao, Guilin Univ. of Electronic Technology (China) 
$68332 \mathrm{M}$ Design of intelligent fault diagnosis system for photoelectric tracking devices based on virtual technology [6833-82]

M. Hou, Institute of Optics and Electronics (China) and Graduate School of the Chinese Academy of Sciences (China); Q. Wu, Institute of Optics and Electronics (China); Y. Liu, Q. Chen, Institute of Optics and Electronics (China) and Graduate School of the Chinese Academy of Sciences (China)

$68332 \mathrm{~N} \quad$ A novel median-contourlet for image denoising application [6833-85]

J. He, K. Gao, G. Ni, Beijing Institute of Technology (China)

683320 Protocols conversion in remote controlling for CCD camera [6833-88]

J. Lin, J. Liu, Y. Wang, Beijing Institute of Technology (China); L. Yang, Mintron Enterprise Co. Ltd. (Taiwan)

$68332 \mathrm{P}$ An ARM-based wavefront processor for adaptive optical system [6833-91] L. Ma, Institute of Optics and Electronics (China) and Graduate School of Chinese Academy of Sciences (China); S. Chen, Institute of Optics and Electronics (China); Y. Liu, Institute of Optics and Electronics (China) and Graduate School of Chinese Academy of Sciences (China); B. Xu, M. Li, Institute of Optics and Electronics (China)

$683325 \quad$ Image analyzing and processing of the patterns in dielectric barrier discharge [6833-95] H. Wang, L. Dong, W. Liu, Y. He, Hebei Univ. (China)

6833 2T A new strategy for object-identification based on its inherent geometrical characteristic [6833-98]

Y. Lin, Y. Xie, Tianjin Univ. (China); Y. Cui, Hebei Univ. of Science and Technology (China);

Y. Huang, Tianjin Univ. (China)

$68332 \mathrm{U} \quad$ Algorithm for fractional multiple image enlargement based on all phase DCT [6833-100] Y. He, Z. Hou, C. Wang, Tianjin Univ. (China)

$68332 \mathrm{~W} \quad$ A study of computer vision for ground surface roughness evaluation [6833-109]

X. Liu, C. Wu, L. Wang, L. Liu, P. Wang, Harbin Univ. of Science and Technology (China)

$68332 \mathrm{X} \quad$ Monitoring vegetation phenology using improved MODIS products [6833-111]

Y. Shuai, Beijing Normal Univ. (China) and Boston Univ. (USA); C. B. Schaaf, A. H. Strahler, Boston Univ. (USA); X. Li, Beijing Normal Univ. (China) and Boston Univ. (USA); F. Gao, NASA Goddard Space Flight Ctr. (USA); J. Liu, National Oceanic and Atmospheric Administration (USA); R. E. Wolfe, NASA Goddard Space Flight Ctr. (USA); J. Wang, Beijing Normal Univ. (China); X. Zhang, National Oceanic and Atmospheric Administration (USA); Q. Zhu, Beijing Normal Univ. (China)

$68332 Y \quad 3 D$ structure recovery from uncalibrated image sequence [6833-114] D. Fu, J. Zhou, L. Li, H. Zhang, Q. Yu, National Univ. of Defense Technology (China)

$68332 Z$ Hyperion true color images mosaic [6833-116]

L. Jiang, X. Chen, G. Ni, D. Xu, H. Li, Beijing Institute of Technology (China)

683330 An image fusion method based on biorthogonal wavelet [6833-121]

J. Li, J. Yu, Shanghai Institute of Technical Physics (China) and Graduate Univ. of Chinese Academy of Sciences (China); S. Sun, Shanghai Institute of Technical Physics (China) 
683331 Comparison and research of spectral response characteristic of transmission-mode GaAs photocathode before and after indium seal [6833-126]

Y. Du, Y. Ji, Univ. of Bingzhou (China); X. Du, Chongqing Univ. (China)

683332 Study of lip-reading detecting and locating technique [6833-127]

L. Wang, J. Li, Changchun Univ. (China); Y. Zhao, Changchun Univ. of Technology (China)

683334 Study on defect detection of IC wafer based on morphology [6833-131]

A. Hou, W. Zhou, G. Cui, D. Shi, K. Xu, L. Zhang, J. Liu, Changchun Univ. of Technology (China)

683335 Study on multi-description coding for ROI medical image based on EBCOT [6833-132] A. Hou, L. Zhang, D. Shi, G. Cui, K. Xu, W. Zhou, J. Liu, Changchun Univ. of Technology (China)

683336 Image retrieval using color and edge histograms [6833-133]

D. Shi, L. Xu, Q. Wang, Changchun Univ. of Technology (China)

683337 Research of image recognition in embedded system based on TM1300 [6833-134]

X. Feng, C. Chang, Wuhan Institute of Technology (China)

683339 Driving techniques for high frame rate CCD camera [6833-140]

W. Guo, Changchun Institute of Optics, Fine Mechanics and Physics (China) and Graduate School of the Chinese Academy of Sciences (China); L. Jin, Graduate School of the Chinese Academy of Sciences (China); J. Xiong, Changchun Institute of Optics, Fine Mechanics and Physics (China)

6833 3A Study of image processing system based on parallel structure of multiple DSPs [6833-143] J. Song, Institute of Optics and Electronics (China) and Graduate Univ. of the Chinese Academy of Sciences (China); Q. Wu, Graduate Univ. of the Chinese Academy of Sciences (China)

6833 3B Fluvial particle characterization using artificial neural network and spectral image processing [6833-149]

B. P. Shrestha, B. Gautam, Kathmandu Univ. (Nepal); M. Nagata, Univ. of Miyazaki (Japan)

6833 3C Computational analysis of Pelton bucket tip erosion using digital image processing [6833-150]

B. P. Shrestha, B. Gautam, Kathmandu Univ. (Nepal); T. R. Bajracharya, Tribhuwan Univ. (Nepal)

Author Index 
Downloaded From: https://www.spiedigitallibrary.org/conference-proceedings-of-spie on 26 Apr 2023

Terms of Use: https://www.spiedigitallibrary.org/terms-of-use 


\title{
Symposium Committees
}

\author{
General Chairs \\ Brian Culshaw, University of Strathclyde (United Kingdom) \\ Bingkun Zhou, Tsinghua University (China) and COS-Chinese Optical \\ Society (China) \\ General Cochairs
}

Arthur Chiou, National Yang-Ming University (Taiwan, China)

Mitsuo Takeda, University of Electro-Communications (Japan)

Chungli Bai, Chinese Academy of Sciences (China)

Seung-Han Park, Yonsei University (South Korea)

Zhizhan Xu, Shanghai Institute of Optics and Fine Mechanics

(China)

Jianlin Cao, China Ministry of Science and Technology (China)

Junhao Chu, Shanghai Institute of Technical Physics (China)

Jingming Kuang, Beijing Institute of Technology (China)

Xiaomin Ren, Beijing University of Posts and Telecommunications (China)

Dingbo Kuang, Shanghai Institute of Technical Physics (China)

Guozheng Yang, Institute of Physics (China)

Honorary Chairs

Daheng Wang, Chinese Academy of Sciences (China)

Guoguang Mu, Nankai University (China)

Technical Program Chair

Songlin Zhuang, Shanghai University of Science and Technology (China)

Technical Program Cochairs

Xun Hou, Xian Institute of Optics and Precision Mechanics (China)

Qian Mao, Wuhan Research Institute of Posts and Telecommunications (China)

Xu Liu, Zhejiang University (China)

Local Organizing Committee Chair

Shusen Xie, Fujian Normal University (China)

Local Organizing Committee Cochairs

Guoqiang Ni, Beijing Institute of Technology (China)

Qihuang Gong, Peking University (China)

Ying Gu, PLA General Hospital (China)

Huilin Jiang, Changchun University of Science and Technology (China) 
General Secretary

Guoqiang Ni, Beijing Institute of Technology (China)

Administrative Vice General Secretary

Boyu Ding, Beijing Institute of Technology (China)

Vice General Secretaries

Hanyi Zhang, Tsinghua University (China)

Ya Cheng, Shanghai Institute of Optics and Fine Mechanics (China)

Zhongwei Fan, Academy of Opto-electronics (China)

Jianxin Chen, Fujian Normal University (China)

Lan Wu, Zhejiang University (China)

Shaowen Wang, COS-Chinese Optical Society (China)

Yuejin Zhao, Beijing Institute of Technology (China)

Chongxiu Yu, Beijing University of Posts and Telecommunication (China)

Jun Ruan, China Solid State Lighting Research and Industry Alliance

(China)

Local Organizing Committee Members

Kangnan Qi, Beijing Optical Society (China)

Chunqing Gao, Beijing Institute of Technology (China)

Tiegen Liu, Tianjin University (China)

Lanxing Shao, Shanghai Optical Society (China)

Zaixuan Zhang, Chinese Jiliang University (China)

Hongda Chen, Institute of Semiconductors (China)

Baosheng Liu, Beijing Optical Society (China)

Xin Wang, Hubei Optical Society (China)

Lin Zhai, COS-Chinese Optical Society (China)

Zhiqiang Zhu, East China Normal University (China)

Lei Xu, Fudan University (China)

Hezhou Wang, Zhongshan University (China)

Zhiming Yi, Ofstar Tech Company, Ltd., Shenzhen (China) 


\title{
Conference Committee
}

\author{
Conference Chairs
}

Liwei Zhou, Beijing Institute of Technology (China)

Chung-Sheng Li, IBM Corporation (USA)

Minerva M. Yeung, Intel Corporation (USA)

Program Committee

Oscar C. L. Au, Hong Kong University of Science and Technology (Hong Kong China)

Edward Y. Chang, University of California, Santa Barbara (USA)

Pao-Chi Chang, National Central University (Taiwan)

Shih-Fu Chang, Columbia University (USA)

Yuan-Chi Chang, IBM Thomas J. Watson Research Center (USA)

Arbee L. P. Chen, National Tsing Hua University (Taiwan)

Janet Chen, Arcadyan (Taiwan)

Liang-Gee Chen, National Taiwan University (Taiwan)

Ming-Syan Chen, National Taiwan University (Taiwan)

Tsuhan Chen, Carnegie Mellon University (USA)

Tihao Chiang, National Chiao Tung University (Taiwan)

Tzi-cker Chiveh, Stony Brook University (USA)

Julia Chung, National Cheng Kung University (Taiwan)

Yeong-Ho Ha, Kyungpook National University (South Korea)

Xun Hou, Xi'an Institute of Optics and Precision Mechanics (China)

Chiou-Ting Hsu, National Tsing Hua University (Taiwan)

Chung-Lin Huang, National Tsing Hua University (Taiwan)

Thomas S. Huang, University of Illinois at Urbana-Champaign (USA)

Sun-Yuan Kung, Princeton University (USA)

C.-C. J. Kuo, University of Southern California (USA)

Victor O. K. Li, The University of Hong Kong (Hong Kong China)

Wanjiun Liao, National Taiwan University (Taiwan)

Rainer W. Lienhart, Universität Augsburg (Germany)

Bede Liu, Princeton University (USA)

Wei-Ying Ma, Microsoft Research Asia (China)

Bangalore S. Manjunath, University of California, Santa Barbara (USA)

Ouhyoung Ming, National Taiwan University (Taiwan)

Sanjit K. Mitra, University of California, Santa Barbara (USA)

Jun Ohya, Waseda University (Japan)

Soo-Chang Pei, National Taiwan University (Taiwan)

Timothy Shih, Tamkang University (Taiwan)

Kang G. Shin, University of Michigan (USA)

Harold S. Stone, NEC Research Institute (USA) 
Ming-Ting Sun, University of Washington (USA)

Chua-Chin Wang, National Taiwan University (Taiwan)

Yao Wang, Polytechnic University (USA)

Yuan-Fang Wang, University of California, Santa Barbara (USA)

Stephen T. C. Wong, Brigham and Women's Hospital (USA)

Ja-Ling Wu, National Taiwan University (Taiwan)

Aidong Zhang, University at Buffalo (USA)

HongJiang Zhang, Microsoft Research Asia (China)

Dazun Zhao, Beijing Institute of Technology (China)

\author{
Session Chairs \\ $1 \quad$ Electronic Imaging Systems \\ Yangqiu Li, Beijing Institute of Technology (China) \\ 2 Image Processing I \\ Xiang Peng, Shenzhen University (China) and Tianjin University (China) \\ 3 Image Processing II \\ Kecong Ai, Xi'an Institute of Applied Optics (China) \\ 4 Target Detection and Image Registration \\ Yangqiu Li, Beijing Institute of Technology (China) \\ $5 \quad$ Image Recognition and Fusion \\ Xiang Peng, Shenzhen University (China) and Tianjin University (China) \\ 6 Color Image Processing and Coding \\ Kecong Ai, Xi'an Institute of Applied Optics (China)
}




\section{Introduction}

Eleven years ago, in 1996, the Conference on Electronic Imaging and Multimedia Systems was added to Photonics Asia Symposium, which is sponsored by the Chinese Optical Society and SPIE. The purpose of this new conference was to provide a forum where participants could disseminate and exchange ideas and present up-to-date comprehensive assessments of progress and developments in the field of electronic imaging and multimedia systems. To this end, it is very gratifying to us that we have been assembled here five times for an informative exchange of opinions.

The Conference on Electronic Imaging and Multimedia Systems focuses on new and exciting topics such as optoelectronic imaging, image analysis, computer vision and pattern recognition, including image acquisition, computer software, algorithms, digital techniques, and applications illustrating the core technologies spanning this increasingly diverse field of research.

Through advances in photonics, optoelectronics, and computing that have taken place during the last 11 years, we found that the electronic imaging and multimedia technologies have created new and interesting technical possibilities in a wide range of fields, such as medicine and healthcare, defense and aerospace, environment, entertainment, commerce, and public safety. This, in turn, has promoted development of technologies necessary for affordable imaging and visualization systems.

Collected in this Volume 6833 of the SPIE proceedings are 103 papers accepted for presentation at the conference. Papers included in these proceedings fall into the following topics: optoelectronic imaging systems; sensors, cameras, and systems for industrial/scientific applications; image quality and system performance; 3D image acquisition and generation techniques; stereoscopic displays and applications; video analysis and processing; image data communication; real-time image processing; visualization and data analysis; visual communications; security and measurement of multimedia content; target detection and tracking; feature extraction, image recognition and classification, image registration and matching, image restoration and segmentation, image fusion, algorithms and systems; machine vision applications; and color imaging processing and applications. These proceedings will no doubt benefit not only the participants of this meeting but also our colleagues engaged in relevant research and development. 
In closing, we would like to heartily thank all of the authors for their contributions to the conference and this volume of proceedings, and all of the participants and friends for their interest and efforts in helping us to make this meeting possible.

\section{Liwei Zhou Chung-Sheng li Minerva M. Yeung}

